\title{
A method for manufacturing superior set yogurt under reduced oxygen conditions
}

\author{
H. Horiuchi, ${ }^{* 1}$ N. Inoue, ${ }^{*}$ E. Liu, ${ }^{*}$ M. Fukui, ${ }^{*}$ Y. Sasaki, $†$ and T. Sasaki $†$ \\ ${ }^{*}$ Research and Development Center, and \\ †Food Science Institute, Meiji Dairies Corporation, 540 Naruda, Odawara, Kanagawa 250-0862, Japan
}

\begin{abstract}
The yogurt starters Lactobacillus delbrueckii ssp. bulgaricus and Streptococcus thermophilus are wellknown facultatively anaerobic bacteria that can grow in oxygenated environments. We found that they removed dissolved oxygen (DO) in a yogurt mix as the fermentation progressed and that they began to produce acid actively after the DO concentration in the yogurt mix was reduced to $0 \mathrm{mg} / \mathrm{kg}$, suggesting that the DO retarded the production of acid. Yogurt fermentation was carried out at 43 or $37^{\circ} \mathrm{C}$ both after the DO reduction treatment and without prior treatment. Nitrogen gas was mixed and dispersed into the yogurt mix after inoculation with yogurt starter culture to reduce the DO concentration in the yogurt mix. The treatment that reduced DO concentration in the yogurt mix to approximately $0 \mathrm{mg} / \mathrm{kg}$ beforehand caused the starter culture LB81 used in this study to enter into the exponential growth phase earlier. Furthermore, the combination of reduced DO concentration in the yogurt mix beforehand and incubation at a lower temperature $\left(37^{\circ} \mathrm{C}\right)$ resulted in a superior set yogurt with a smooth texture and strong curd structure.
\end{abstract}

Key words: yogurt manufacture, set yogurt, dissolved oxygen, fermentation

\section{INTRODUCTION}

Fermentation is one of the oldest methods for extending the shelf life of milk (Tamime and Robinson, 1999). The definition of yogurt given in the Food and Agriculture Organization of the United Nations/World Health Organization standards (FAO/WHO, 1984) is as follows: "Yogurt is the coagulated milk product obtained by lactic acid fermentation through the action of Lactobacillus delbrueckii ssp. bulgaricus (L. bulgaricus)

Received September 24, 2008.

Accepted May 11, 2009.

${ }^{1}$ Corresponding author: hiroshi_horiuchi@meiji-milk.com and Streptococcus thermophilus (Strep. thermophilus) from milk and milk products. The microorganisms in the final product must be viable and abundant." Such a product is beneficial to human health (Tamime and Robinson, 1999). Michaylova et al. (2007) suggested that the Strep. thermophilus and L. bulgaricus strains that are widely used for commercial yogurt production could have originated from plants in Bulgaria.

Modern industrial yogurt is classified into 2 types. One is stirred or drinking yogurt, and the other is set yogurt. The former is produced by fermenting the yogurt in a tank, and then packaging the yogurt mix into individual containers. The latter is produced by packaging the yogurt mix into individual containers before fermentation. The global sales of yogurt in 2006 were approximately US $\$ 40$ billion, and the sales of yogurt in Japan in 2006 were approximately US $\$ 2.4$ billion, approximately US $\$ 1.1$ billion of which were sales of set yogurt.

There is great demand for set yogurt in Japan. As a commercial product, it is important that the set yogurt has curd with sufficient hardness to stand up to the impact caused by shaking during transport by truck to long-distance markets. Nielsen (1975) suggested that the texture of set yogurt should be firm enough to remove it from the container with a spoon. It is evident that the fastest rate of acid production and the curd with the desired firmness are obtained when the yogurt starter culture is incubated at 40 to $45^{\circ} \mathrm{C}$ (Tamime and Robinson, 1999), and in general, industrial yogurt fermentation is carried out at 40 to $45^{\circ} \mathrm{C}$. A good set yogurt should have both a hard curd and a smooth texture. Mehanna (1991) suggested that the required incubation time for making zabadi (Egyptian yogurt with a mixed culture of Strep. thermophilus and L. bulgaricus) increased with decreasing incubation temperature and that the preparation of zabadi at 30 or $35^{\circ} \mathrm{C}$ improved smoothness and minimized curd syneresis. With respect to sensory qualities, Cho-Ah-Ying et al. (1990) suggested that a set yogurt incubated at $38^{\circ} \mathrm{C}$ was smoother than yogurt incubated at $43^{\circ} \mathrm{C}$. Driessen (1984) suggested that the starter culture might produce more polysaccharides with low-temperature fermentation, which contributes 
Table 1. Strains used

\begin{tabular}{lcc}
\hline & \multicolumn{2}{c}{ Strain $^{1}$} \\
\cline { 2 - 3 } Mixed culture & $\begin{array}{c}\text { Lactobacillus delbrueckii } \\
\text { name }\end{array}$ & $\begin{array}{c}\text { Streptococcus } \\
\text { thermophilus }\end{array}$ \\
\hline LB81 & 2038 & 1131 \\
A1 & 1106 & 3074 \\
A2 & 1589 & 3078 \\
A3 & OLL1073R-1 & 1131 \\
\hline
\end{tabular}

${ }^{1}$ Each strain number represents the culture collection number of the Food Research and Development Center, Meiji Dairies Corporation (Kanagawa, Japan).

to a smoother perceived texture. However, there are 2 problems with fermentation at $38^{\circ} \mathrm{C}$ : fermentation takes a much longer time, which decreases productivity, and the set yogurt curd becomes weak.

The yogurt starter culture of L. bulgaricus and Strep. thermophilus are facultatively anaerobic, so the fermentation of yogurt with these bacteria progresses well in the presence of oxygen. The majority of lactic acid bacteria strains, including the 4 genera Streptococcus, Leuconostoc, Pediococcus, and Lactobacillus, are aerotolerant to some degree (Condon, 1987). Sakamoto and Komagata (1996) reported that most of the 22 strains of lactic acid bacteria, including the genera Lactobacillus, Pediococcus, Leuconostoc, Streptococcus, and Enterococcus, grew well under aerobic conditions. The effect of the initial level of dissolved oxygen (DO) on acid production in buffalo milk by different single lactic cultures of Streptococcus lactis, Streptococcus diacetylactis, Streptococcus cremoris, L. bulgaricus, and Streptococcus thermophilus was tested by Shekar and Bhat (1983). They reported that rates of acid production in buffalo milk by these lactic cultures increased with the decrease in initial oxygen content from 5.50 to $2.90 \mathrm{mg} / \mathrm{kg}$, and that incorporating oxygen into milk to increase the initial oxygen content from 5.50 to $9.00 \mathrm{mg} / \mathrm{kg}$ strongly inhibited acid production. Kawasaki et al. (2006) investigated the effects of oxygen on Bifidobacterium species of using liquid shaking cultures under various oxygen concentrations. They reported that although most of the Bifidobacterium species showed oxygen sensitivity, 2 species, B. boum and B. thermophilum, showed growth stimulation in the presence of oxygen. Driessen et al. (1982) suggested that L. bulgaricus Ib needed the carbon dioxide produced by Strep. thermophilus for optimal growth in milk.

Although many studies have been conducted on the influence of oxygen on lactic acid bacteria, only a small number of studies have reported on the influence of oxygen on yogurt fermentation with a mixed culture of L. bulgaricus and Strep. thermophilus in yogurt manu- facture. In this work, we investigated the influence of oxygen on yogurt fermentation with L. bulgaricus 2038 and Strep. thermophilus 1131. We developed a rapid-set yogurt fermentation method that involved reducing the DO concentration in the yogurt mix to approximately $0 \mathrm{mg} / \mathrm{kg}$ beforehand and then incubating the mix at a lower temperature. The combination of reduced DO and lower temperature brought about a better set yogurt with a smooth texture and a strong curd structure.

\section{MATERIALS AND METHODS}

\section{Culture Strains Used}

As shown in Table 1, four kinds of yogurt starter cultures, comprising a total of 7 strains of $L$. bulgaricus and Strep. thermophilus, were used in this study. These strains were obtained from the culture collection of the Food Research and Development Center, Meiji Dairies Corporation. The culture LB81, which contains $L$. bulgaricus 2038 and Strep. thermophilus 1131, was the most frequently used in this study. This starter culture has been used in the commercial production of Meiji Bulgaria Yogurt LB81 in Japan since 1993. In addition, the cultures A1, A2, and A3 were used.

\section{Preparation of Yogurt Bulk Starter}

Each strain of L. bulgaricus or Strep. thermophilus stored at $-80^{\circ} \mathrm{C}$ was subcultured once at $37^{\circ} \mathrm{C}$ for 16 $\mathrm{h}$ in skim milk and yeast extract (SMY) medium, composed of $10 \%$ (wt/wt) skim milk supplemented with $0.1 \%$ (wt/wt) yeast extract (preculture) after autoclaving $\left(121^{\circ} \mathrm{C}, 7 \mathrm{~min}\right)$, and was cooled to $5^{\circ} \mathrm{C}$. Both precultures of L. bulgaricus and Strep. thermophilus were inoculated (1\%; wt/wt) into fresh, sterilized SMY medium $\left(95^{\circ} \mathrm{C}, 10 \mathrm{~min}\right)$, incubated at $37^{\circ} \mathrm{C}$ to reach an acidity of $0.7 \%$, and cooled immediately to $5^{\circ} \mathrm{C}$ (yogurt bulk starter culture). The acidity was measured by titrating a 9-g sample against $0.1 N$ sodium hydroxide using phenolphthalein as the indicator. The yogurt starter culture was then stored at $5^{\circ} \mathrm{C}$. The yogurt starter culture LB81, which was maintained at $5^{\circ} \mathrm{C}$, was used until $3 \mathrm{~d}$ after preparation.

\section{Preparation of Yogurt}

The method of yogurt preparation was based on a laboratory-scale manufacturing process commonly conducted at the Food Research and Development Center of Meiji Dairies Corporation. The yogurt mix used in this study, which contained $3.0 \%$ (wt/wt) fat and $9.5 \%$ (wt/wt) SNF, was obtained by mixing raw milk [3.6\% 
(wt/wt) fat], skim milk powder, butter $[80.0 \%$ (wt/ wt) fat], and water. These materials were supplied by the plants of Meiji Dairies Corporation. After being homogenized at $15 \mathrm{MPa}$, the yogurt mix was heated to $95^{\circ} \mathrm{C}$ for 2 min and immediately cooled to 43 or $37^{\circ} \mathrm{C}$. The yogurt bulk starter was inoculated in the yogurt mix to a concentration of $2 \%$. After mixing, $90 \mathrm{~g}$ of the mixture was placed into ten $100-\mathrm{mL}$ polystyrene cups that were oxygen permeable. Fermentation was carried out at 43 or $37^{\circ} \mathrm{C}$. The yogurt fermentation end point was set at $0.7 \%$ acidity. The yogurt fermentation time was the time required for the original acidity of $0.2 \%$ to change to the end point of $0.7 \%$. Yogurt samples were stored at $5^{\circ} \mathrm{C}$ for $1 \mathrm{~d}$ before analysis.

\section{Fermentation Method Under Reduced Oxygen Conditions}

The DO reduction process was as follows. After yogurt starter culture inoculation, sterile nitrogen gas (filtered with a $0.45-\mu \mathrm{m}$ cellulose acetate filter) was aseptically mixed and dispersed into the yogurt mix through a stainless steel pipe (approximately 3-mm bore) to reduce DO concentration in the yogurt mix to nearly $0 \mathrm{mg} / \mathrm{kg}$. Concentration of DO in the yogurt mix was measured with a DO meter (DO-24P, DKK-TOA Corp., Tokyo, Japan).

Yogurt fermentation was carried out at 43 or $37^{\circ} \mathrm{C}$ both after the DO reduction treatment and without prior treatment. Yogurt fermentation at 43 and that at $37^{\circ} \mathrm{C}$ without prior treatment are referred to as the control fermentation at $43^{\circ} \mathrm{C}$ and the control fermentation at $37^{\circ} \mathrm{C}$, respectively. Yogurt fermentation after the reduced DO treatment at 43 and that at $37^{\circ} \mathrm{C}$ are referred to as reduced DO fermentation (ROF) and low-temperature ROF (LT-ROF), respectively.

\section{Physical Characterization of Yogurt}

The properties of yogurt samples were measured after $24 \mathrm{~h}$ of storage at $5^{\circ} \mathrm{C}$. The $\mathrm{pH}$ was measured with a $\mathrm{pH}$ meter (HM-50V, DKK-TOA Corp.).

The physical properties of yogurt smoothness and hardness were measured by using a curd meter (ME-302, Iio denki, Tokyo, Japan). However, there is no optimal method for evaluating the smoothness of set yogurt. The ME-302 curd meter is specially designed to evaluate the hardness of set yogurt and can also be used for evaluating smoothness. Specifically, the surface angle formed by the pressure of a yogurt knife with a weight of $100 \mathrm{~g}$ was measured. Here, the weight at which the elastic surface curve was broken and penetration occurred was defined as hardness (g), whereas the angle of that curve (the penetration angle) was used as an indicator of smoothness (with the angle having a value from 0 to $90^{\circ}$, and with smaller values representing a smoother tissue). Three yogurt samples were analyzed at each trial and average readings were taken.

The degree of whey syneresis of yogurt was defined as the ratio (\%) of the volume of supernatant after centrifugation $\left(2,150 \times g, 10 \mathrm{~min}, 5^{\circ} \mathrm{C}\right)$ to yogurt sample. This method helped us estimate rapidly and in advance the actual whey syneresis of the yogurt after storage.

\section{Microbiological Analysis}

To count the viable cells of yogurt bacteria, aliquots of the yogurt sample after $1 \mathrm{~d}$ of storage at $5^{\circ} \mathrm{C}$ were poured onto plates and mixed with $15 \mathrm{~mL}$ of bromocresol purple plate count agar (Eiken Chemical Co. Ltd., Tokyo, Japan) that had been autoclaved and kept at $50^{\circ} \mathrm{C}$. The plates were incubated at $37^{\circ} \mathrm{C}$ for $72 \mathrm{~h}$. The colonies of L. bulgaricus and Strep. thermophilus were identified by their rough shape and their smooth shape, respectively, in the agar plates.

\section{Sensory Evaluation}

Two yogurt samples in $100-\mathrm{mL}$ cups were made either by the control fermentation method at $43^{\circ} \mathrm{C}$ or by the LT-ROF method and were stored at $5^{\circ} \mathrm{C}$ for 1 $\mathrm{d}$ before evaluation. The sensory evaluation was carried out with 200 consumers according to the following method. Yogurt consumers were recruited and 200 panelists were selected. The panelists consisted of 50 males and 50 females who regularly consume yogurt 1 to 3 times a week and 50 males and 50 females who consume yogurt 4 times a week or more. Each panelist evaluated only one kind of yogurt at a session. Panelists evaluated both a control yogurt and a yogurt made by the LT-ROF method for smoothness, sourness, and mildness at 2 sessions. Sessions were held at least $1 \mathrm{~h}$ apart. The absolute evaluation data (scored 1 through 5 for either sample) and results were analyzed using $z$-tests (Lawless and Heymann, 1998).

\section{RESULTS}

\section{Reduction of DO Concentration in the Yogurt Mix During Fermentation}

The change in DO concentration in the yogurt mix during fermentation was measured with the yogurt starter culture LB81, which was composed of $L$. bulgaricus 2038 and Strep. thermophilus 1131. Kinetics of the DO concentration in the yogurt mix with LB81 are shown in Figure 1. As shown in this figure, the DO concentration in the yogurt mix was approximately 6 


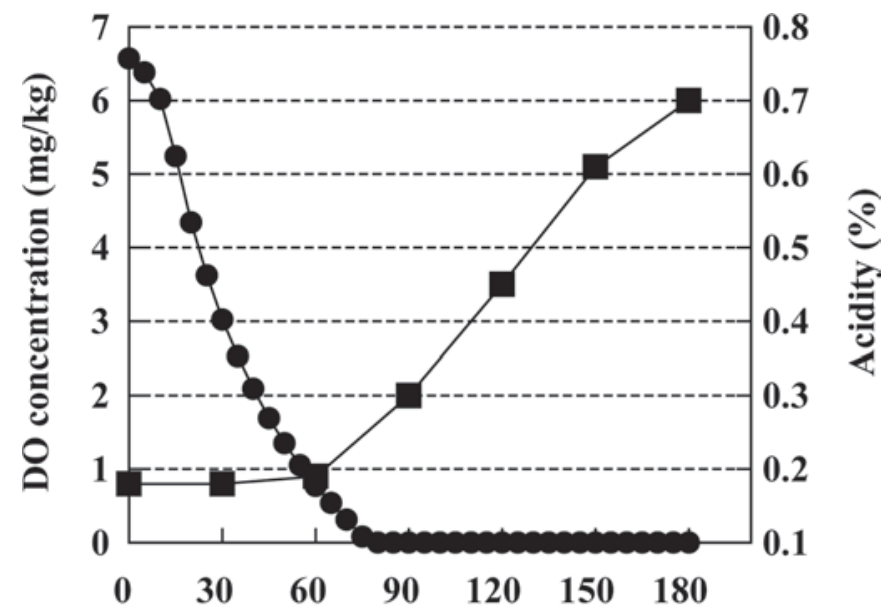

Fermentation time (min)

Figure 1. Acid production and variation of dissolved oxygen (DO) concentration kinetics of LB81. Incubation at $43^{\circ} \mathrm{C}$. ( $\bullet$ DO concentration and (ם) acidity.

$\mathrm{mg} / \mathrm{kg}$ at the beginning of fermentation at $43^{\circ} \mathrm{C}$, and was gradually reduced as fermentation progressed. The time required for the DO concentration to be reduced from 6 to $0 \mathrm{mg} / \mathrm{kg}$ was approximately $60 \mathrm{~min}$. The original acidity in the yogurt mix was approximately $0.2 \%$. The starter culture LB81 actively began to produce acid after the DO concentration in the yogurt mix was reduced to $0 \mathrm{mg} / \mathrm{kg}$.

We then examined whether other yogurt starter cultures also began to produce acid actively after the DO concentration of the yogurt mix was reduced. The kinetics of acid production and the DO concentration in the yogurt mix were analyzed with 3 other yogurt starter cultures, A1, A2, and A3 (Table 1). All 3 cultures began to produce acid actively after the DO concentration had been reduced to about $0 \mathrm{mg} / \mathrm{kg}$ after approximately $60 \mathrm{~min}$. From these results, we concluded that yogurt starter cultures composed of L. bulgaricus and Strep. thermophilus generally began to produce acid rapidly after the DO had decreased to almost $0 \mathrm{mg} / \mathrm{kg}$.

Next, we examined the possibility that the yogurt mix without cultures could reduce the DO. The change in DO concentration in a yogurt mix was measured with a heat-killed $\left(80^{\circ} \mathrm{C}, 10 \mathrm{~min}\right)$ culture and a culture without LB81. The results showed that the DO concentration in the yogurt mix was approximately $6 \mathrm{mg} / \mathrm{kg}$ both before and after incubation at $43^{\circ} \mathrm{C}$ for $5 \mathrm{~h}$. Similar results were also obtained for the $\mathrm{A} 1, \mathrm{~A} 2$, and $\mathrm{A} 3$ cultures. From these experiments, we considered that only the living starter culture bacteria could reduce the DO in the yogurt mix.

In addition, the change in DO concentration in the yogurt mix during fermentation with a single starter culture of L. bulgaricus 2038 or Strep. thermophilus 1131 was measured. The DO concentration in the yogurt mix decreased as fermentation progressed, as in the case of LB81 (data not shown).

\section{Acid Production Under Constant DO Concentration}

From these results, we hypothesized that DO interferes with rapid acid production in yogurt manufacturing. Therefore, we examined whether acid production was suppressed under a constant DO concentration by using a jar fermenter. Because acid production by the LB8 1 starter culture began after the DO concentration had decreased to almost $0 \mathrm{mg} / \mathrm{kg}$, we assumed that DO in the yogurt mix had inhibited acid production.

To evaluate the influence of DO on acid production precisely, cultivation under constant DO concentrations when using a jar fermenter was examined. The changes in acidity and $\mathrm{pH}$ are shown in Figure $2 \mathrm{~A}$ and $2 \mathrm{~B}$. The acidity produced by LB81 after incubation at $43^{\circ} \mathrm{C}$ for 150 min with DO concentration in the yogurt mix fixed at $4,2,1$, and $0 \mathrm{mg} / \mathrm{kg}$ by adjusting the air or nitrogen gas bubbling into the yogurt mix was $0.2,0.2,0.3$, and $0.7 \%$, respectively. These experiments showed that acid production by LB81 was suppressed greatly with $1 \mathrm{mg} /$ $\mathrm{kg}$ or more of DO in the yogurt mix and was promoted with $0 \mathrm{mg} / \mathrm{kg}$. However, acid production by L. bulgaricus 2038 or Strep. thermophilus 1131 alone was neither suppressed nor advanced by the DO concentration in the yogurt mix (Figure 3). We observed that in the case of the single culture L. bulgaricus 2038 or Strep. thermophilus 1131, the acid production rate under aerobic conditions $(6 \mathrm{mg} / \mathrm{kg})$ was almost the same as that under anaerobic conditions $(0 \mathrm{mg} / \mathrm{kg})$.

In addition, whether acid production was also suppressed by the other yogurt starter cultures under a constant substantial DO concentration was examined. The acidity after fermentation for $150 \mathrm{~min}$ by the yogurt starter cultures A1, A2, and A3 at a DO concentration of $4 \mathrm{mg} / \mathrm{kg}$ was less than $0.2 \%$. It is probable that acid production by the yogurt starter culture is generally suppressed when there is at least $4 \mathrm{mg} / \mathrm{kg}$ of DO in the yogurt mix. The above explains that DO interferes with rapid acid production not only by LB81, but also by other yogurt starter cultures in yogurt manufacturing.

\section{Fermentation Under Reduced DO}

From the results obtained above, we assumed that acid production might be accelerated after the DO concentration in the yogurt mix had been reduced to nearly $0 \mathrm{mg} / \mathrm{kg}$ because there would be no suppression caused by the DO. The following experiments were examined. 
A

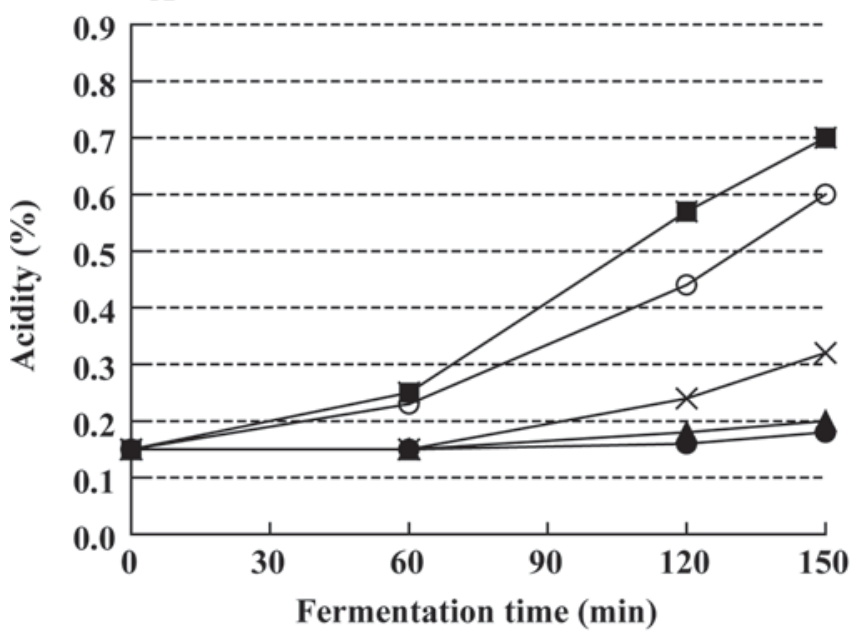

B

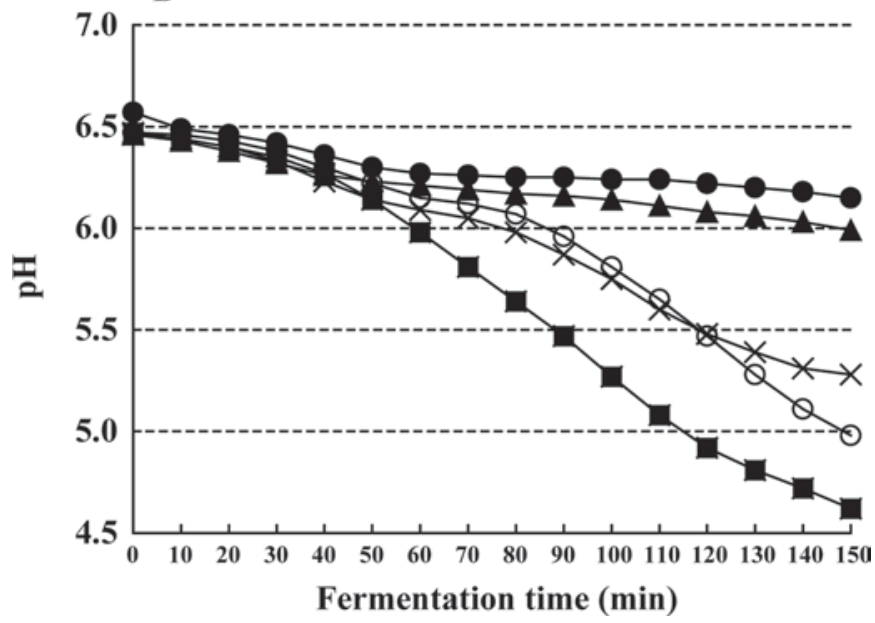

Figure 2. Influence of dissolved oxygen (DO) concentration on the acid production by yogurt culture LB 81 incubated at $43^{\circ} \mathrm{C}$. Acid production was measured through changes in titratable acidity (A) or $\mathrm{pH}$ (B). Incubation of LB81 under DO concentration fixed at $4(\bullet), 2(\boldsymbol{\Delta})$, $1(\times)$, and $0 \mathrm{mg} / \mathrm{kg}(\boldsymbol{\square})$ and under normal air conditions $(\mathrm{O})$.

The effect of reducing DO on acid production velocity was examined. As shown in Figure 4, the acid production by $\mathrm{LB} 81$ at $43^{\circ} \mathrm{C}$ was promoted by reducing the DO concentration in the yogurt mix to nearly 0 $\mathrm{mg} / \mathrm{kg}$. The time required for acidity in the yogurt mix to reach $0.7 \%$ was approximately 30 min less than in the control fermentation at $43^{\circ} \mathrm{C}$. The acid production rate was almost the same, but the starting point of acid production in the fermentation with the reduced DO was 30 min earlier than in the control. This new fermentation method is referred to as ROF.

Several properties of the yogurt samples were checked after $1 \mathrm{~d}$ of storage at $5^{\circ} \mathrm{C}$. The viable cell counts of L. bulgaricus 2038 and Strep. thermophilus 1131 of the yogurt made by ROF were $1.2 \times 10^{8}$ and $4.7 \times 10^{8}$ $\mathrm{cfu} / \mathrm{g}$, and were almost the same as in the yogurt made by the control fermentation at $43^{\circ} \mathrm{C}\left(1.1 \times 10^{8}\right.$ and 4.5 $\left.\times 10^{8} \mathrm{cfu} / \mathrm{g}\right)$. There were also no differences in other properties (acidity, curd tension, and $\mathrm{pH}$ ) between the yogurt made by ROF and the control fermentation at $43^{\circ} \mathrm{C}$ (data not shown). These results indicate that the yogurt made by ROF had almost the same characteristics as the yogurt made by the control fermentation at $43^{\circ} \mathrm{C}$; thus, ROF was a favorable faster yogurt production method.

During these experiments, we found that the yogurt bulk starter culture of LB81 made by ROF maintained rapid acid production for a longer time than that made by the control fermentation. As shown in Figure 5, the velocity of acid production using the 7-d-old bulk starter culture of LB81 prepared by the control fermentation decreased compared with the 3-d starter culture. However, the 7-d-old bulk starter culture of LB81 prepared by ROF showed almost the same velocity of acid production as the 3 - $\mathrm{d}$ culture.

\section{LT-ROF}

Encouraged by these results, we applied this rapid fermentation method to the control fermentation at $37^{\circ} \mathrm{C}$ (low-temperature fermentation). It is well known that yogurt made by low-temperature fermentation has a smooth texture, but the fermentation process takes a much longer time than the control fermentation at $43^{\circ} \mathrm{C}$, and this longer time lowers the efficiency of yogurt manufacturing. Thus, experiments combining ROF and low-temperature fermentation were carried out. As shown in Figure 6, the time required for acidity to reach $0.7 \%$ was 220 min with the control fermentation at $37^{\circ} \mathrm{C}$, whereas it was 180 min with the LT-ROF. The time for the acidity of the yogurt mix to reach $0.7 \%$ at $37^{\circ} \mathrm{C}$ was decreased by approximately $40 \mathrm{~min}$ by reducing the DO.

\section{Characteristics of Yogurt Prepared by LT-ROF}

The fermentation time at $37^{\circ} \mathrm{C}$ was shortened by reducing the DO (LT-ROF), so next we compared the characteristics of yogurt prepared by LT-ROF and by the control fermentation at $37^{\circ} \mathrm{C}$. The viable cell counts of L. bulgaricus 2038 and Strep. thermophilus 1131 of the yogurt made by LT-ROF were $1.0 \times 10^{8}$ and $7.9 \times$ $10^{8} \mathrm{cfu} / \mathrm{g}$, which were nearly the same as those by the control fermentation at $37^{\circ} \mathrm{C}$. The acidity and $\mathrm{pH}$ of the yogurt stored at $5^{\circ} \mathrm{C}$ for $1 \mathrm{~d}$ after fermentation were essentially the same, but the appearance of these 2 yogurt samples was quite different. As shown in Figure 7, when scooped up with a spoon, the yogurt made by the control fermentation at $37^{\circ} \mathrm{C}$ collapsed easily, but the yogurt made by LT-ROF was firm. The results of the 


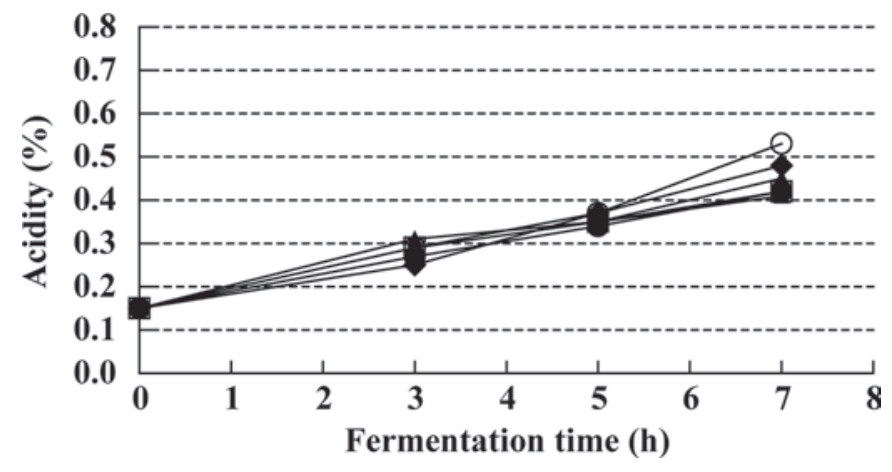

Figure 3. Influence of dissolved oxygen (DO) concentration on the acid production by the single yogurt cultures Streptococcus thermophilus 1131 and Lactobacillus delbrueckii ssp. bulgaricus 2038 incubated at $43^{\circ} \mathrm{C}$. Acid production was measured through changes in titratable acidity. Each of the cultures was incubated under a DO concentration fixed at 6 or $0 \mathrm{mg} / \mathrm{kg}$. Symbols: $\bullet$ Streptococcus thermophilus 1131 control, $(\bullet) 6 \mathrm{mg} / \mathrm{kg}$, and $(\boldsymbol{\Delta}) 0 \mathrm{mg} / \mathrm{kg}$. Lactobacillus bulgaricus 2038 $(\diamond)$ control, $(\bigcirc) 6 \mathrm{mg} / \mathrm{kg}$, and $(\square) 0 \mathrm{mg} / \mathrm{kg}$.

sensory test of set yogurt with 200 consumers showed that the yogurt made by LT-ROF had a higher score with respect to the characteristics "smooth texture" and "mild taste" compared with the yogurt made by the control fermentation at $43^{\circ} \mathrm{C}$ (Table 2).

The yogurt made by LT-ROF had nearly the same smooth texture as the yogurt made by the control fermentation at $37^{\circ} \mathrm{C}$ but, unexpectedly, had an firmer curd. To express these physical properties with numerical values, 2 methods were then used. First, the degree of whey syneresis of yogurt (\%) was measured; this was defined

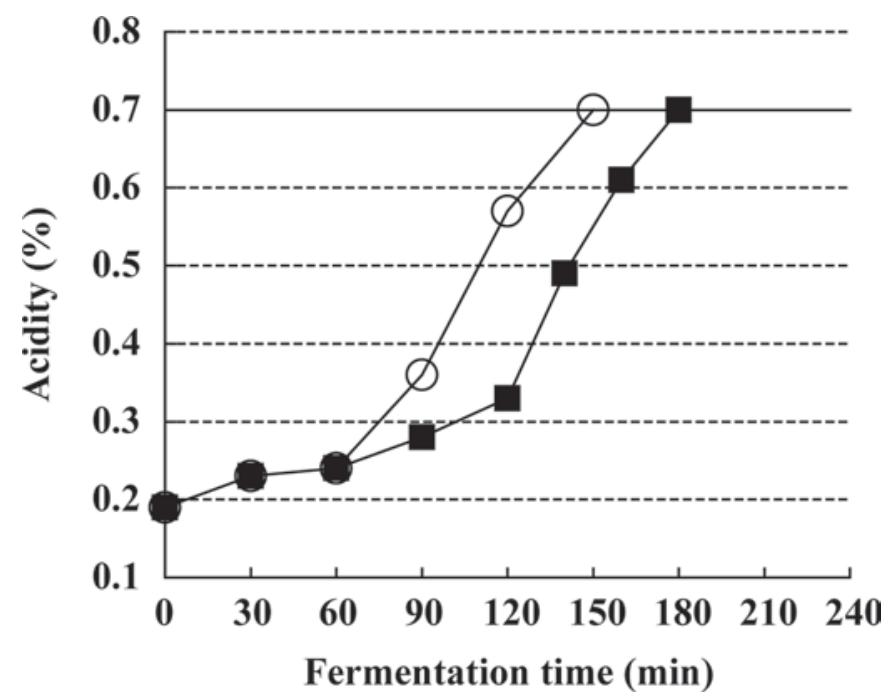

Figure 4. Effect of reduced dissolved oxygen (DO) fermentation (ROF) on acid production by the yogurt culture LB81 when the DO concentration in the yogurt mix was regulated to approximately $0 \mathrm{mg} /$ $\mathrm{kg}$ beforehand. Incubation was at $43^{\circ} \mathrm{C}$. Symbols: (O) ROF at $43^{\circ} \mathrm{C}$ and (ם) the control fermentation at $43^{\circ} \mathrm{C}$. as the ratio of the supernatants obtained by centrifugation $\left(2,150 \times g, 10 \mathrm{~min}, 5^{\circ} \mathrm{C}\right)$ of the yogurt sample. The degree of whey syneresis was in the following sequence: the yogurt made by LT-ROF (approximately 10\%) = the yogurt made by the control fermentation at $37^{\circ} \mathrm{C}$ (approximately 10\%) < the yogurt made by the control fermentation at $43^{\circ} \mathrm{C}$ (approximately 20\%). This result indicates that the yogurt made by LT-ROF had almost the same close structure as the yogurt made by the control fermentation at $37^{\circ} \mathrm{C}$. Second, the hardness and penetration angle of the yogurt curd were determined with a 100-g yogurt knife and the ME-302 curd meter. In our experience, a hardness of $40 \mathrm{~g}$ and greater is sufficient to stand up to the impact of shaking during transport, whereas $30 \mathrm{~g}$ or less is not. The penetration angle could be a value up to $90^{\circ}$, with a smaller value indicating a smoother texture. As shown in Table 3, the hardness and smoothness of the yogurt made by LTROF were $50 \mathrm{~g}$ and $30^{\circ}$, respectively, whereas those of the yogurt made by the control yogurt fermentation at $37^{\circ} \mathrm{C}$ were $30 \mathrm{~g}$ and $30^{\circ}$. This indicated that the yogurt made by LT-ROF had better physical properties for consumers than the latter.

\section{Application of LT-ROF to Industrial Yogurt Manufacture}

Application of LT-ROF was carried out on an industrial scale. A scale-up test of LT-ROF was carried out with 5 tons of yogurt mix in a yogurt plant of Meiji Dairies Corporation. The time and characteristics of the laboratory-scale $(500-\mathrm{mL})$ and the industrial-scale fermentation were compared. It took $180 \mathrm{~min}$ for the acidity of the yogurt mix to reach $0.7 \%$ in the plant test, nearly the same as in the laboratory test. The viable cell counts of L. bulgaricus and Strep. thermophilus, acidity, curd tension, $\mathrm{pH}$, and sensory properties of yogurt manufactured in the plant were nearly the

Table 2. A sensory test with 200 yogurt consumers was carried out on yogurt made by low-temperature reduced dissolved oxygen fermentation (LT-ROF; A) and yogurt made by the control fermentation method at $43^{\circ} \mathrm{C}(\mathrm{B})$, served in $100-\mathrm{mL}$ cups

\begin{tabular}{llc}
\hline & \multicolumn{2}{c}{ Score $^{1}$} \\
\cline { 2 - 3 } Term & $\mathrm{A}$ & $\mathrm{B}$ \\
\hline Smoothness & $4.25^{*}$ & 3.91 \\
Sourness & 2.96 & 3.13 \\
Mildness & $3.94^{* *}$ & 3.46 \\
\hline
\end{tabular}

${ }^{1}$ The absolute evaluation data were scored 1 through 5 for both the control and test yogurt for their smoothness $(1=$ not at all, $5=$ very smooth), sourness $(1=$ weak, $5=$ strong $)$, and mildness $(1=$ not at all, $5=$ very mild $)$.

${ }^{*} P<0.05 ;{ }^{* *} P<0.01$. 


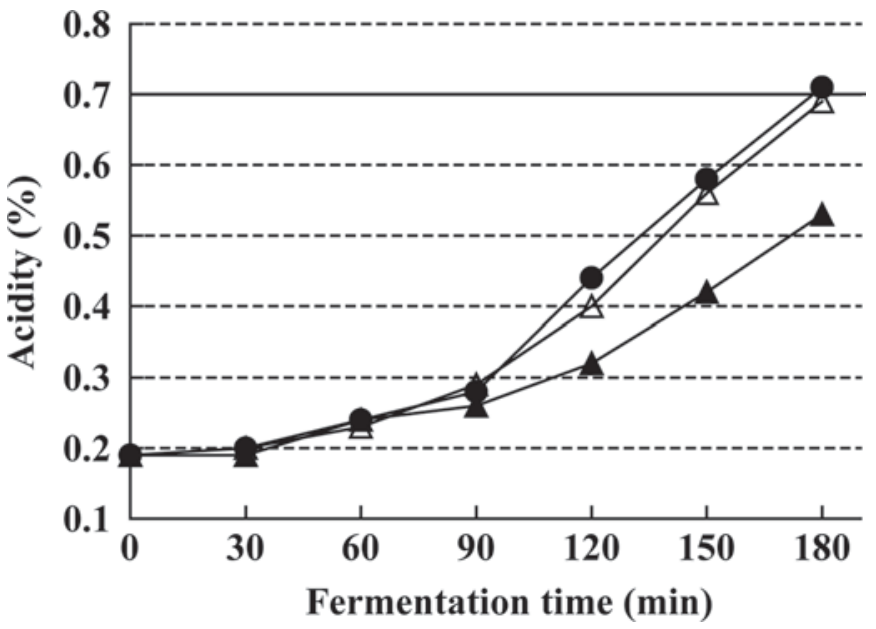

Figure 5. Preservation of acid productive activity of the bulk starter made by reduced dissolved oxygen fermentation (ROF). Incubation was at $43^{\circ} \mathrm{C}$. Symbols: $(\bullet)$ LB81 starter maintained at $5^{\circ} \mathrm{C}$ for $3 \mathrm{~d}$ with the control fermentation; ( $\mathbf{\Delta}) \mathrm{LB} 81$ starter maintained at $5^{\circ} \mathrm{C}$ for $7 \mathrm{~d}$ with the control fermentation; $(\Delta)$ LB81 starter maintained at $5^{\circ} \mathrm{C}$ for $7 \mathrm{~d}$ with the ROF.

same as for the yogurt made in the laboratory (data not shown).

Because the yogurt made in the plant is distributed throughout the national market, it is important that the structure of the yogurt is sufficiently hard to stand up to the impact caused by shaking during transport. Thus, a long-distance (approximately 1,000-km) transport test by refrigerated truck was carried out with 720 containers of yogurt manufactured by LT-ROF in one of the Meiji Dairies Corporation plants. The results showed no yogurt broken up after the 1,000-km transport.

\section{DISCUSSION}

\section{Influence of DO on the Yogurt Fermentation Progress}

The DO in the yogurt mix was reduced as yogurt fermentation by the starter culture LB81 progressed. Because the DO concentration in the yogurt mix was not reduced either with heat-killed LB81 or without LB81, we concluded that the starter culture of live bacteria reduced DO in the yogurt mix. Marty-Teysset et al. (2000) suggested that L. bulgaricus could reduce oxygen into hydrogen peroxide with its reduced nicotinamide adenine dinucleotide oxidase (NADH), thereby possibly eliminating the oxygen that is present. Kawasaki et al. (1998) suggested that even the obligatory anaerobic bacteria Clostridium butyricum JCM1391 possesses the ability to consume oxygen, although it does not grow while it is consuming oxygen in the medium. After consumption of all the DO, $C$. butyricum JCM1391 resumes growth at a rate similar to its normal anaerobic growth rate. We found that the starter culture LB81 could not start active acid production before the DO concentration in the yogurt mix was reduced to $0 \mathrm{mg} / \mathrm{kg}$. Moreover, when even 1 $\mathrm{mg} / \mathrm{kg}$ of DO remained in the yogurt mix, the rate of acid production by LB81 was much lower, almost the same as the sum of acid produced by 2 single cultures of L. bulgaricus 2038 and Strep. thermophilus 1131 (data not shown). We concluded that DO did not interfere with the growth of these single cultures; on the other hand, DO did stop rapid acid production because of the symbiosis of the single cultures.

The other yogurt starter cultures A1, A2, and A3 also began to produce acid rapidly after the DO concentration in the yogurt mix had been reduced to approximately $0 \mathrm{mg} / \mathrm{kg}$. It may be concluded that the yogurt starter cultures composed of L. bulgaricus and Strep. thermophilus generally begin to produce acid rapidly, presumably based on their symbiosis after the DO concentration of the yogurt mix has been reduced to nearly $0 \mathrm{mg} / \mathrm{kg}$.

\section{Fermentation Time Abridgement by ROF}

The discussion above explains why the DO in the yogurt mix is a barrier to acid production by the yogurt starter culture LB81. It was concluded that acid production by LB81 can be greatly accelerated by reducing DO in the yogurt mix before fermentation.

In our tests, the DO in the yogurt mix was reduced beforehand, which resulted in a 30-min reduction of

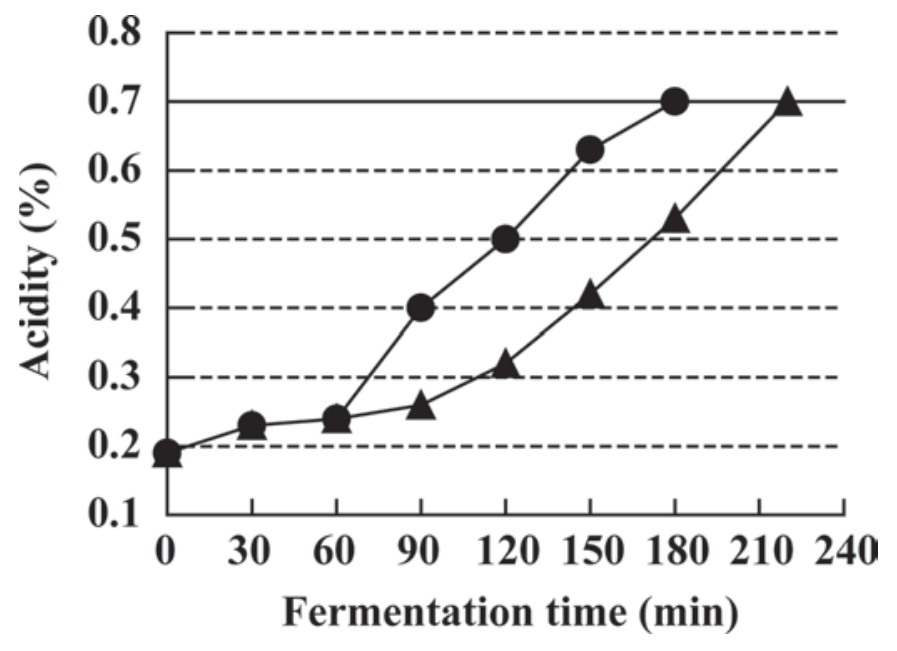

Figure 6. Effect of low-temperature reduced dissolved oxygen (DO) fermentation (LT-ROF) on acid production by the yogurt culture LB81 when the DO concentration in the yogurt mix was regulated to approximately $0 \mathrm{mg} / \mathrm{kg}$ beforehand. Incubation was at $37^{\circ} \mathrm{C}$. Symbols: $(\bullet)$ LT-ROF and $(\boldsymbol{\Lambda})$ control fermentation at $37^{\circ} \mathrm{C}$. 
Table 3. Mean values $( \pm \mathrm{SD})$ of the physical properties of yogurt made by low-temperature reduced dissolved oxygen fermentation (LT-ROF) and yogurt made by the control fermentation at 37 or $43^{\circ} \mathrm{C}$

\begin{tabular}{lcc}
\hline & \multicolumn{2}{c}{ Physical properties of the yogurt $^{1}$} \\
\cline { 2 - 3 } Yogurt production & Hardness $(\mathrm{g})$ & Penetration angle $\left(^{\circ}\right)$ \\
\hline Yogurt made by LT-ROF & $50 \pm 8$ & $30 \pm 2$ \\
Yogurt made by control fermentation at $37^{\circ} \mathrm{C}$ & $29 \pm 2$ & $30 \pm 1$ \\
Yogurt made by control fermentation at $43^{\circ} \mathrm{C}$ & $50 \pm 4$ & $57 \pm 3$ \\
\hline
\end{tabular}

${ }^{1}$ Physical properties of the yogurt are defined in the Materials and Methods section.

the fermentation time needed for the acidity of the yogurt mix to reach to $0.7 \%$ when using LB81 as the starter culture. Galesloot et al. (1968) suggested that the oxygen in the air suppresses acid production by the yogurt culture. Here, we examined the suppression of acid production by DO quantitatively by fermentation under constant DO concentrations when using a jar fermenter and found that even $1 \mathrm{mg} / \mathrm{kg}$ of DO could suppress acid production by LB81.

It was concluded that the fermentation was accelerated by ROF because the time necessary for the starter culture LB81 to reduce the DO was shortened. By reducing the DO beforehand, the symbiosis of the bacteria was promoted. The time required for the LB81 starter culture to reduce the DO reduction was approximately $60 \mathrm{~min}$, but the yogurt fermentation time was nevertheless cut by only 30 min with ROF. This time lag might have been due to the time required for activation of the starter culture.

In addition, whether the acid production rate with other yogurt starter cultures could be accelerated by ROF was examined. The fermentation time with starter culture A3 was reduced by $30 \mathrm{~min}$ with ROF, but it was not reduced with A1 or A2 at all. Contrary to our expectations, the fermentation acceleration effect of ROF did not apply to all starter cultures of $L$. bulgaricus and Strep. thermophilus. The reason for this phenomenon is not clear at present.

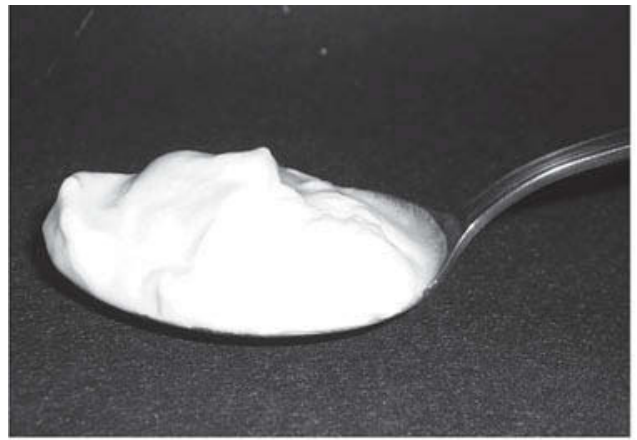

Control fermentation at $37^{\circ} \mathrm{C}$
We also found that the ROF method brought an additional important economic advantage to yogurt manufacture; that is, the yogurt bulk starter prepared by ROF could be used twice a long as that prepared by the control method.

\section{LT-ROF}

Two problems are encountered in introducing lowtemperature fermentation (control fermentation at $37^{\circ} \mathrm{C}$ ) into the industrial-scale manufacture of set yogurt. One is the longer time of the fermentation process and the other is insufficient yogurt curd hardness.

Because the yogurt fermentation time was reduced with ROF, we tried combining ROF with the control fermentation at $37^{\circ} \mathrm{C}$ (low temperature fermentation). We concluded that the texture of yogurt incubated at $37^{\circ} \mathrm{C}$ was smoother than the yogurt incubated at $43^{\circ} \mathrm{C}$ because the acid production at $37^{\circ} \mathrm{C}$ proceeded more slowly than at $43^{\circ} \mathrm{C}$. The higher temperature of incubation might accelerate the aggregation of the $\mathrm{CN}$ micelles, resulting in a coarse protein network (Green, 1984).

Surprisingly, it turned out that although acid production by LT-ROF was faster, it could make a smoother yogurt. Our explanation for this is as follows. Our investigation revealed that yogurt curd formation began after the acidity reached approximately $0.4 \%$ for a yogurt

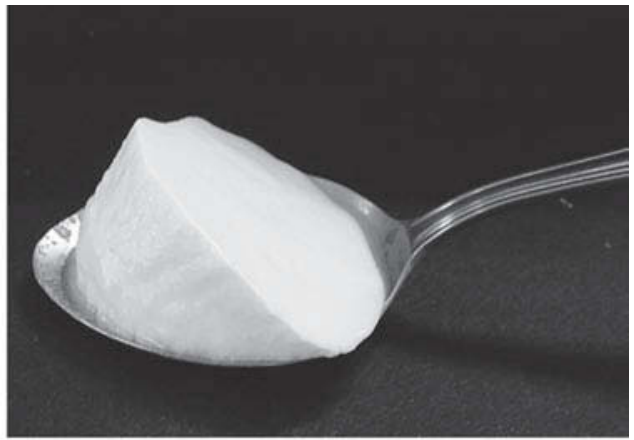

LT-ROF

Figure 7. Appearance of the yogurt made by low-temperature reduced dissolved oxygen (DO) fermentation (LT-ROF) and the control fermentation at $37^{\circ} \mathrm{C}$, when scooped up with a spoon. 
Table 4. Comparison of yogurt curd formation times among 3 fermentation methods

\begin{tabular}{lcc}
\hline Fermentation method & $\begin{array}{c}\text { Yogurt curd } \\
\text { formation } \\
\operatorname{time}^{1}(\min )\end{array}$ & $\begin{array}{c}\text { Yogurt } \\
\text { fermentation } \\
\text { time }^{2}(\min )\end{array}$ \\
\hline LT-ROF $^{3}$ & 90 & 180 \\
Control fermentation at $37^{\circ} \mathrm{C}$ & 70 & 220 \\
Control fermentation at $43^{\circ} \mathrm{C}$ & 50 & 180 \\
\hline
\end{tabular}

${ }^{1}$ Yogurt curd formation time $(\mathrm{min})$ : fermentation began at $0.2 \%$ acidity and yogurt curd formation began from $0.4 \%$ acidity. Because the fermentation end point was set at $0.7 \%$ acidity, the yogurt curd formation time was the time for the acidity to increase from 0.4 to $0.7 \%$. Yogurt curd formation times are shown in Figures 4 and 6.

${ }^{2}$ Yogurt fermentation time ( $\left.\mathrm{min}\right)$ : the time for the acidity to increase from 0.2 to $0.7 \%$.

${ }^{3}$ Low-temperature reduced dissolved oxygen fermentation.

mix that contained $9.5 \% \mathrm{SNF}$ (wt/wt), and because the yogurt fermentation end point was set at $0.7 \%$ acidity, the curds formed in the time during which the acidity of the yogurt mix was changing from 0.4 to $0.7 \%$. This period is referred to as the yogurt curd formation time and it is presumed that the longer curd formation time makes the texture of the yogurt smoother. As shown in Table 4, although the time of fermentation by LT-ROF was among the shortest of the 3 methods (180 min, equal to the control fermentation at $43^{\circ} \mathrm{C}$ ), its curd formation time was the longest. The curd formation time with LT-ROF was 90 min, whereas with the other methods it was 50 and $70 \mathrm{~min}$. We hypothesized that this was the reason the yogurt made by the LT-ROF method was very smooth in spite of its short fermentation time.

In our experiments, indications of yogurt smoothness depended mainly on the sensory evaluation because no standard method exists for measuring the physical properties of set-type yogurt. We proposed that the assessment of yogurt texture could be quantified based on 2 factors: one was measurement of the degree of whey syneresis, and the other was the penetration angle of a yogurt knife with a weight of $100 \mathrm{~g}$ into the yogurt curd (ME-302 curd meter).

\section{Application of LT-ROF to Industrial Yogurt Manufacture}

In the yogurt plant, all stages in the yogurt manufacturing process are consecutive and are controlled by an automatic system so that the efficiency of manufacture is lowered considerably by extension or variation of fermentation time by even $10 \mathrm{~min}$. In particular, fermentation is the stage that takes the longest time. The control fermentation process at $37^{\circ} \mathrm{C}$ took 40 min longer than the control fermentation process at $43^{\circ} \mathrm{C}$. This has prevented the introduction of low-temperature fermen- tation methods into commercial yogurt manufacture. This problem was solved by using LT-ROF (Figure 6).

The set-type yogurt previously made by low-temperature fermentation had insufficient hardness to stand up to the impact of shaking during transport. This problem was also solved by using LT-ROF. The yogurt made by LT-ROF had sufficient hardness to stand up to the impact caused by shaking during transport (Table $3)$. The reason for this is not clear.

Moreover, the LT-ROF process can easily be introduced into ordinary yogurt plants because this requires only setting up a system for injecting sterile nitrogen gas into the yogurt mix to eliminate oxygen and adjusting the fermentation temperature. Meiji Dairies Corporation sold 4 kinds of yogurt products made by LT-ROF on the Japanese market in 2008.

\section{CONCLUSIONS}

Starter culture LB81, composed of L. bulgaricus and Strep. thermophilus, reduced the DO in the yogurt mix before acid formation. The starter began to produce acid actively after the DO concentration in the yogurt mix had been reduced to nearly $0 \mathrm{mg} / \mathrm{kg}$. Fermentation with LB81 was suppressed by the presence of more than $1 \mathrm{mg} / \mathrm{kg}$ of DO in the yogurt mix. We conclude that DO interferes with the symbiotic relationship between L. bulgaricus and Strep. thermophilus. We found that reducing the DO concentration in the yogurt mix with LB81 to nearly $0 \mathrm{mg} / \mathrm{kg}$ reduced the fermentation time at $43^{\circ} \mathrm{C}$ compared with the control fermentation at $43^{\circ} \mathrm{C}$.

The set yogurt made by the control fermentation at $37^{\circ} \mathrm{C}$ (low-temperature fermentation) had a smooth texture but had insufficient hardness to stand up to the impact of shaking during transport. Moreover, this low-temperature fermentation took a much longer time, which reduced the yogurt manufacturing efficiency. Combining ROF with low-temperature fermentation (LT-ROF) reduced the time required for low-temperature fermentation, and the yogurt made by the LT-ROF method also had sufficient hardness.

A more precise evaluation of yogurt quality, especially a sensory evaluation, may be needed to confirm these findings, which we will perform in the very near future. However, we believe that LT-ROF is a favorable method for industrial-scale manufacture of set yogurt that possesses a smooth texture and strong curd structure.

\section{ACKNOWLEDGMENTS}

The authors thank Youichi Niimura and Shinji Kawasaki of the Department of Bioscience, Tokyo Univer- 
sity of Agriculture (Tokyo, Japan), for their valuable discussions and encouragement.

\section{REFERENCES}

Cho-Ah-Ying, F., C. L. Duitschaever, and C. Buteau. 1990. Influence of temperature of incubation on the physico-chemical and sensory quality of yogurt. Cult. Dairy Prod. J. 25:11-14.

Condon, S. 1987. Response of lactic acid bacteria to oxygen. FEMS Microbiol. Rev. 46:269-281.

Driessen, F. M. 1984. Modern trends in the manufacture of yoghurt. Int. Dairy Fed. Bull. 179:107-115.

Driessen, F. M., F. Kingma, and J. Stadhouders. 1982. Evidence that Lactobacillus bulgaricus in yogurt is stimulated by carbon dioxide produced by Streptococcus thermophilus. Neth. Milk Dairy J. 36:135-144.

FAO/WHO. 1984. Codex Alimentarius: Code of Principles Concerning Milk and Milk Products, International Standards for Milk products and International Individual Standards for Cheese. Codex Alimentarius Commission, Food and Agriculture Organization of the United Nations, and World Health Organization, Rome, Italy.

Galesloot, T. H. E., F. Hasing, and H. A. Veringa. 1968. Symbiosis in yoghurt (1). Stimulation of Lactobacillus bulgaricus by a factor produced by Streptococcus thermophilus. Neth. Milk Dairy J. 22:50-63.

Green, M. L. 1984. Pages 21-23 in Advances in the Microbiology and Biochemistry of Cheese and Fermented Milk. F. L. Davies and B. A. Law, ed. Elsevier Applied Science Publishers, London, UK.

Kawasaki, S., T. Mimura, T. Satoh, K. Takeda, and Y. Niimura. 2006. Response of the microaerophilic Bifidobacterium species, B. boum and B. thermophilum, to oxygen. Appl. Environ. Microbiol. 72:6854-6858.

Kawasaki, S., T. Nakagawa, Y. Nishiyama, Y. Benno, T. Uchimura, K. Komagata, M. Kozaki, and Y. Niimura. 1998. Effect of oxygen on the growth of Clostridium butyricum, and the distribution of enzymes for oxygen and for active oxygen species in clostridia. J. Ferment. Bioeng. 86:368-372.

Lawless, H. T., and H. Heymann. 1998. Sensory Evaluation of Food. International Thomson Publishing, Florence, KY

Marty-Teysset, C., F. de la Torre, and J.-R. Garel. 2000. Increased production of hydrogen peroxide by Lactobacillus delbrueckii subsp. bulgaricus upon aeration: Involvement of an NADH oxidase in oxidative stress. Appl. Environ. Microbiol. 66:262-267.

Mehanna, A. S. 1991. An attempt to improve some properties of Zabadi by applying low temperature long incubation period in the manufacturing process. Egypt. J. Dairy Sci. 19:221-229.

Michaylova, M., M. Svetlana, K. Kimura, T. Sasaki, and K. Isawa. 2007. Isolation and characterization of Lactobacillus delbruecki ssp. bulgaricus and Streptococcus thermophilus from plants in Bulgaria. FEMS Microbiol. Lett. 269:160-169.

Nielsen, V. H. 1975. Factors which control the body and texture of commercial yoghurts. Am. Dairy Rev. 37:36-38.

Sakamoto, M., and K. Komagata. 1996. Aerobic growth of and activities of NADH oxidase and NADH peroxydase in lactic acid bacteria . J. Ferment. Bioeng. 82:210-216.

Shekar, S., and G. S. Bhat. 1983. Influence of dissolved oxygen on acid production in buffalo milk by lactic cultures. J. Food Prot. $46: 321-324$.

Tamime, A. Y., and R. K. Robinson. 1999. Yoghurt Science and Technology. 2nd ed. Woodhead Publishing Limited, Cambridge, UK. 